\title{
When Is the Ideal Period for Herbst Therapy-Early or Late?
}

\author{
Sabine Ruf and Hans Pancherz
}

The present article aims at answering the question whether an early or late treatment approach is the ideal period for Herbst therapy. This topic will be discussed by summarizing and evaluating the short- and long-term effects of the Herbst appliance on the dentofacial complex. Special emphasis will be given to the treatment outcome in relation to the patient's somatic and skeletal maturity at the time of therapy. Furthermore, the long-term stability of the treatment results will be addressed. The available knowledge in the literature demonstrates that the ideal period for Herbst treatment is in the permanent dentition at or just after the peak of pubertal growth corresponding to the skeletal maturity stages FG to $\mathrm{H}$ of the middle phalanx of the third finger (implying the pre-capping to pre-union stages of the ephiphysis and metaphysis). As mandibular growth stimulation is also possible in postadolescent-young adult subjects a new concept of Class II therapy is presented in which the Herbst appliance is used as an alternative to orthognathic surgery in older Class II subjects. (Semin Orthod 2003;9:47-56.) Copyright 2003, Elsevier Science (USA). All rights reserved.

$\boldsymbol{O}$ ne of the goals of dentofacial orthopedics in Class II malocclusions is to eliminate the skeletal jaw base discrepancy by stimulating mandibular growth. In a review article on the effect of functional appliances on skeletal growth, Aelbers and Dermaut ${ }^{1}$ concluded that the Herbst appliance (Fig 1) is the only functional appliance able to influence mandibular length to a biologically significant degree.

In general, Herbst treatment of Class II malocclusions results in a Class I or overcorrected Class I dental arch relationship. The correction of the increased overjet and Class II molar relationship is the result of the following dental and skeletal changes ${ }^{2-5}$ : (1) maxillary growth inhibition, (2) mandibular growth enhancement, (3) maxillary molar distalization and maxillary incisor retrusion and retroclination, and (4) man-

From the Department of Orthodontics, University of Ciessen. Giessen, Germany.

Address correspondence to Sabine Ruf, DDS, PhD, Deparment of Orthodontics, School of Dentistry, University of Berne, Freibure sirasse 7, CII-3010 Berne, Swizerland.

Copynght 2003, Elsevier Science (USA). All rights reserved.

$1073-8746 / 03 / 0901-0001 \$ 35.00 / 0$

doi: $10.1053 / \mathrm{sod} 0.2003 .34024$ dibular molar mesialization and mandibular incisor protrusion and proclination.

Herbst appliance treatment in the department of orthodontics at the University of Giessen is most often performed during the adolescent growth period, which is a time of optimal conditions for growth modification. However, skeletal adaptation is also possible in subjects at the end of growth. ${ }^{6,7}$ However, the question arises as to which is the ideal period relative to growth development (early or late) for (1) maximal mandibular growth stimulation and (2) long-term stability. This question will be addressed in light of information available in the literature.

\section{Overview of Material and Methods}

The interrelation between the amount of mandibular growth contributing to Class II correction and skeletal and/or somatic maturity has been investigated in 6 articles ${ }^{8-13}$ and the longterm stability as well as the factors contributing to Class II relapse in 7 articles. ${ }^{1 \cdot 1-20}$ The material and methods used in the different articles are summarized in Tables 1 and 2. A total of 6 

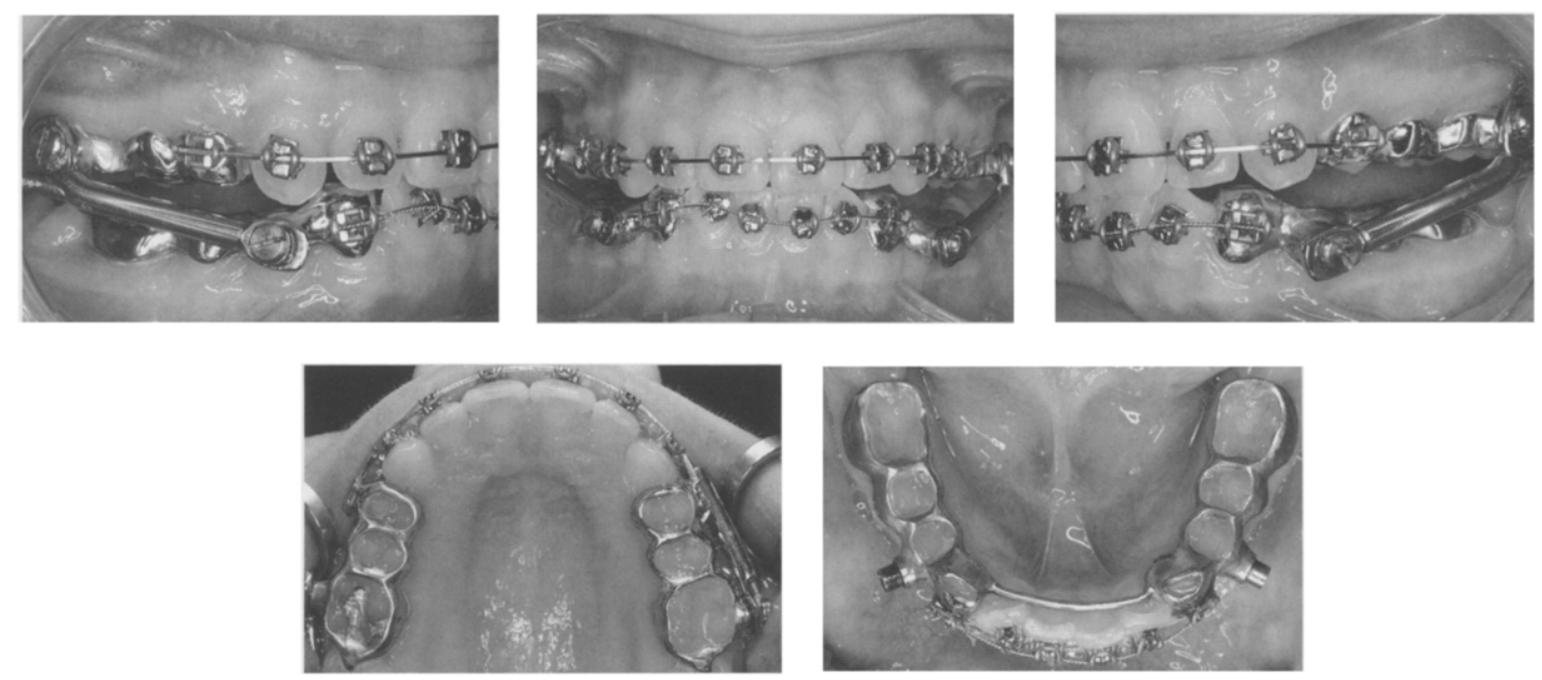

Figure 1. Cast splint Herbst/Multibracket appliance. The bilateral telescope mechanism holds the mandible permanently in an anterior-jumped position.

different cephalometric analyses were used to study the dentoskeletal effects of the Herbst appliance.

In assessing somatic maturity of Herbst patients and control subjects, longitudinal growth records of standing body height over a 5- to 10-year period were analyzed. Individual distance and velocity growth curves were constructed. The peak height velocity of growth was identified on the curves, and at least 3 growth periods were established: prepeak, peak, and postpeak. $8,9,11,12$

Skeletal maturity (Fig 2) was assessed with the help of the radiographic developmental stages of the middle phalanx of the third finger and the radius bone using the method of Hägg and Taranger. ${ }^{21}$

\section{The Ideal Treatment Period for Maximal Mandibular Growth Stimulation}

In all Herbst studies assessing the interrelation between somatic ${ }^{8,9,11,12}$ or skeletal ${ }^{8-10,13}$ maturity and mandibular growth stimulation, a large interindividual variation existed. Nevertheless, a general pattern could be identified showing a steady increase in sagittal condylar growth stimulation from the prepeak to the peak growth period, followed by a steady decline in the postpeak period (Fig 3). Subjects treated at peak or 1 to 2 years after peak exhibited the largest sagittal condylar growth and thus the largest mandibular length increase. , $^{8,11,12}$ Correspondingly, the greatest amount of sagittal condylar growth was found in subjects treated at the skeletal maturity stage MP3-FG (Fig 2), which occurs close to the peak growth period (Fig 4). ${ }^{8,9}$ This pattern was most obvious in boys, whereas in girls no marked differences in skeletal mandibular treatment effects were found when comparing different growth periods. ${ }^{1}$

The increase of sagittal condylar growth in Herbst patients (Figs 3 and 4) was significantly greater than in untreated Class II control subjects. ${ }^{8,11,12}$ Irrespective of the growth period, the difference of mandibular length increase when comparing Herbst and control subjects amounted to an average of $1.3 \mathrm{~mm} .^{8}$ Thus, the increased amount of condylar growth accomplished by the Herbst appliance seems to be the result of an equal additions of enhanced growth to normally occurring condylar growth, irrespective of the somatic or skeletal maturation stage of the patients (Figs 3 and 4). Recent studies on the Herbst appliance have shown that mandibular growth stimulation is due to a remodeling of the condyle and also of the glenoid fossa. The latter can be routinely noted on magnetic resonance images of the TMJ area taken during treatment. ${ }^{7,22}$

It is believed that Class II correction by orthopedic means is not possible after the age of 13.5 years in girls and 15 years in boys because $97 \%$ of the growth is completed at these ages. ${ }^{23}$ However, in using the Herbst appliance, it is possible 


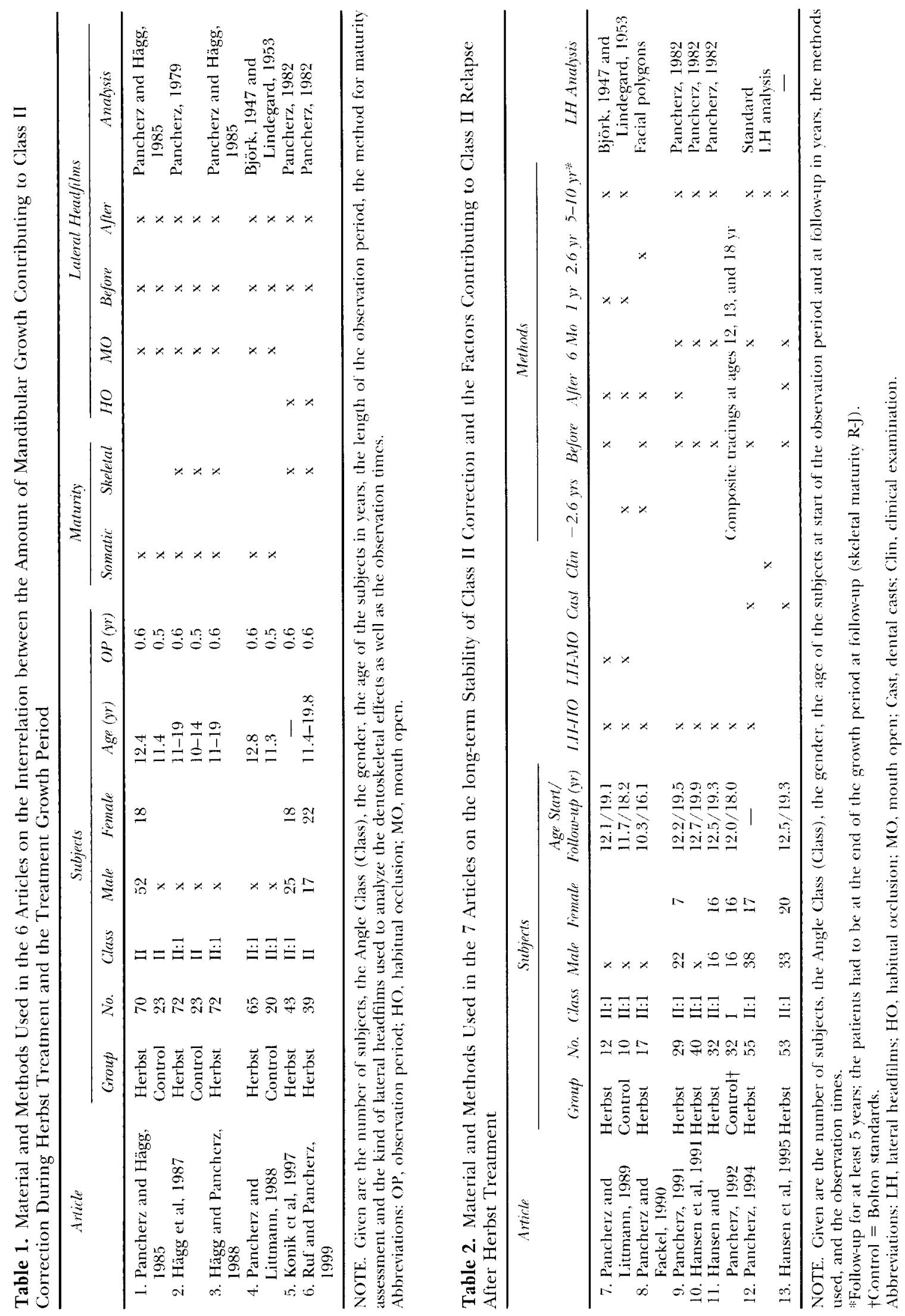




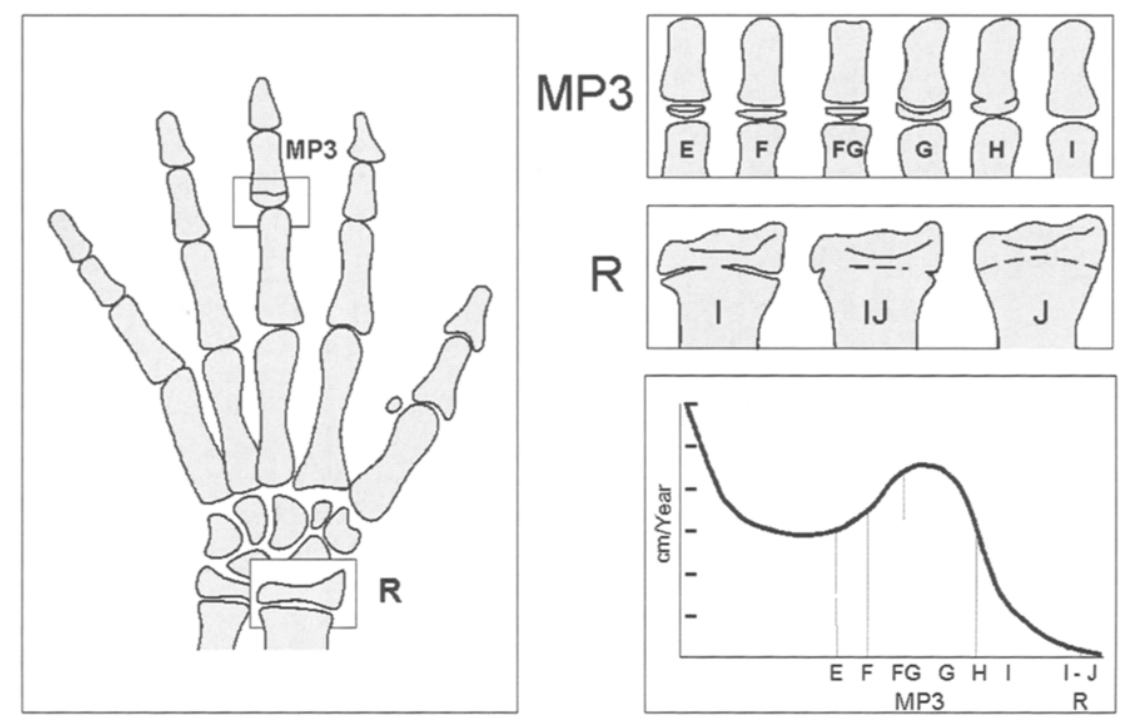

Figure 2. Skeletal maturity stages of the middle phalanx of the third finger (MP3) and the radius ( R) according to Hägg and Taranger ${ }^{21}$ and their interrelation to the pubertal growth velocity is shown. Stage MP3-E, the epiphysis is not yet as wide as the metaphysis. Stage MP3-F: the epiphysis is as wide as the metaphysis. Stage MP3-FG: the epiphysis is as wide as its metaphysis, and there is a distinct medial and/or lateral border of the epiphysis forming a line of demarcation at right angles to the distal border. Stage MP3-G: the sides of the epiphysis have thickened and also cap its metaphysis, forming a sharp edge distally at one or both sides. Stage MP3-H: fusion of epiphysis and metaphysis has begun. Stage MP3-I: fusion of epiphysis and metaphysis is complete. Stage R-I: fusion of epiphysis and metaphysis has begun. Stage R-IJ: fusion is almost completed, but there is a small gap at one or both margins. Stage R-J: fusion of epiphysis and metaphysis is completed.

to reactivate and stimulate condylar growth even in subjects at the end of growth.6,7,13 Although the total amount of mandibular length increase in young adults (skeletal maturity stages R-IJ or RJ, see Fig 2) is less than in adolescents, the amount of stimulated mandibular growth is identical. ${ }^{13}$ This implies that young adult Class II subjects can be treated successfully by means of the Herbst appliance. Thus, the treatment

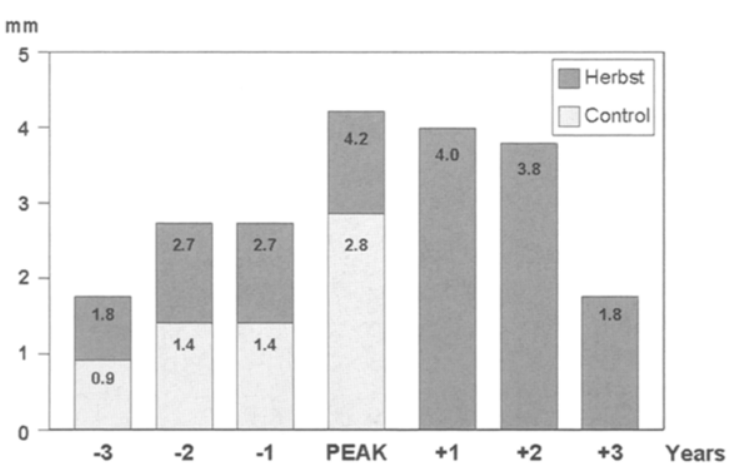

Figure 3. Mandibular growth $(\mathrm{mm})$ relative to the pubertal peak (peak) of growth in 72 male Herbst patients treated for an average period of 7 months and 23 untreated male Class II Control subjects. method could be considered to be an alternative to orthognathic surgery (Fig 5-7).

The relative contribution of skeletal and dental changes contributing to overjet correction varies considerably between individuals irrespective of gender, somatic, or skeletal maturity. ${ }^{9-11,13}$ In subjects with comparably severe Class II malocclu-

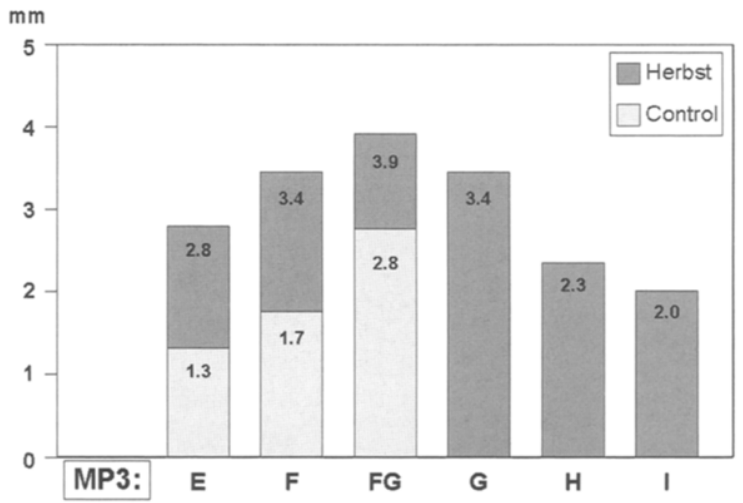

Figure 4. Mandibular growth ( $\mathrm{mm})$ relative to the skeletal maturity in 72 male Herbst patients treated for an average period of 7 months and 23 untreated male Class II Control subjects. 8 

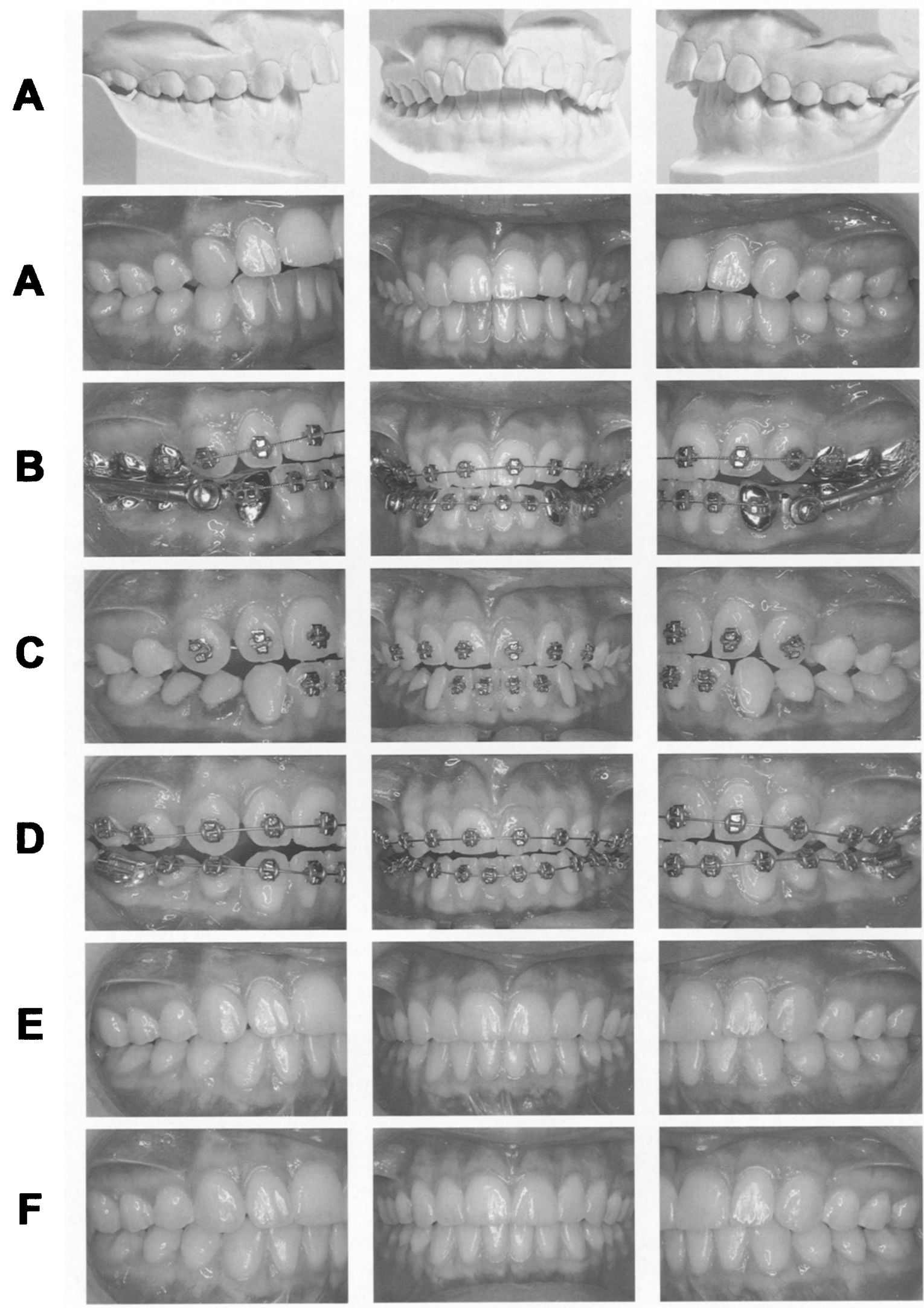

Figure 5. A female Class II, division 1 patient, 19 years of age, treated with a cast splint Herbst/Multibracket appliance system. Dental casts and intraoral photographs from before treatment (A), at start of Herbst treatment (B), after Herbst treatment $(\mathrm{C})$, during multibracket appliance treatment (D), after multibracket appliance treatment $(\mathrm{E})$, and 2 years post multibracket appliance treatment $(\mathrm{F})$. 

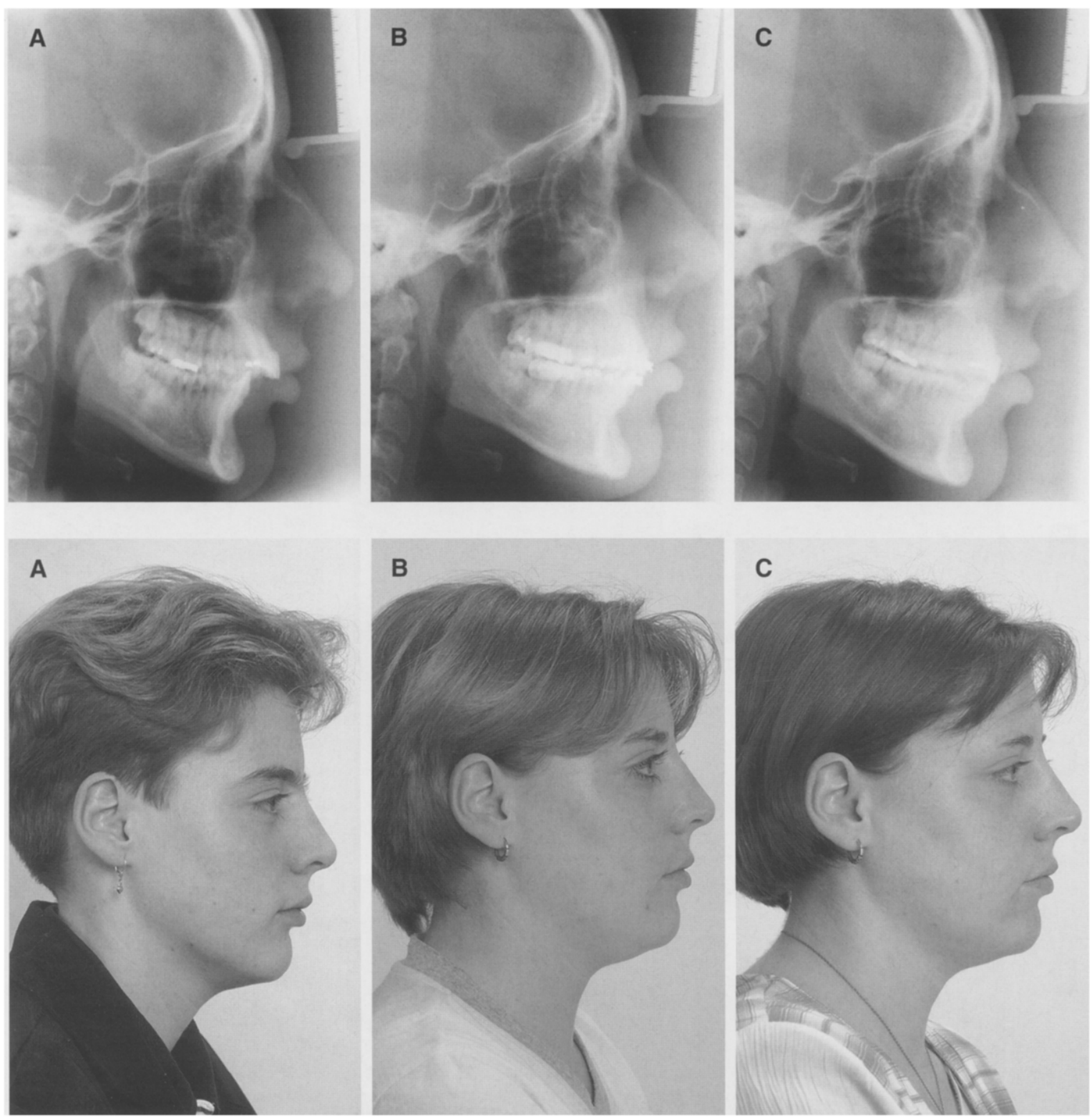

Figure 6. Female Class II, division 1 patient, 19 years of age, treated with a cast splint Herbst/Multibracket appliance system. Lateral headfilms and profile photographs from before treatment (A), 1 week before the end of Herbst/Multibracket appliance treatment (B), and 2 years posttreatment $(\mathrm{C})$.

sions, ${ }^{10,13}$ the largest skeletal effects contributing to overjet correction (Fig 8) were found in the peak period (MP3 FG-G). In postpeak patients (MP3 H-I) and young adults (R IJ-J) especially, the mandibular dental changes increased. ${ }^{13}$

\section{The Ideal Treatment Period for Long-Term Stability}

It has been claimed for a long time that normalizing the skeletal and soft-tissue morphology at an early age would provide a basis for continuing normal development of these structures. ${ }^{24-27}$ This has, however, never been proven. When analyzing Herbst patients 5 to 10 years after treatment, it was found that the total amount of maxillary and mandibular growth was greatest in those Herbst patients treated during the prepeak period. ${ }^{14}$ However, the improvement in sagittal jaw base relationship was found to be comparable between prepeak, peak, and post- 

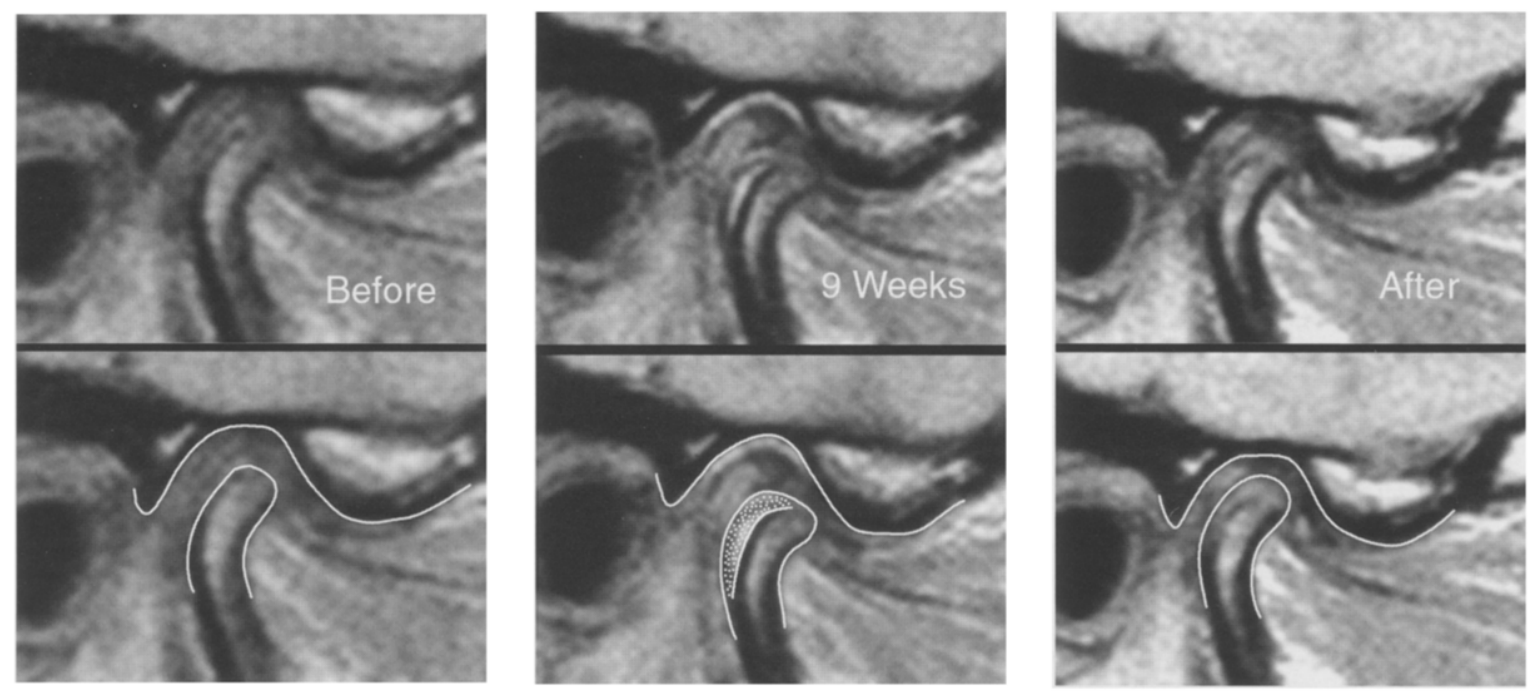

Figure 7. Female Class II, division 1 patient, 19 years of age, treated with a cast splint Herbst/Multibracket appliance system. Parasagittal magnetic resonance images of the right TMJ from before, after 9 weeks and after 8 months of Herbst treatment. Please note condylar remodeling at 9 weeks of treatment.

peak subjects; mandibular growth exceeded maxillary growth by $4.6 \mathrm{~mm}$ in prepeak, $4.2 \mathrm{~mm}$ in peak, and $3.9 \mathrm{~mm}$ in postpeak patients. Thus, the growth period in which the patients were treated did not have a marked influence on the long-term treatment result. ${ }^{14}$

Furthermore, in patients treated with the Herbst appliance, mandibular length increased more than in subjects with ideal occlusions

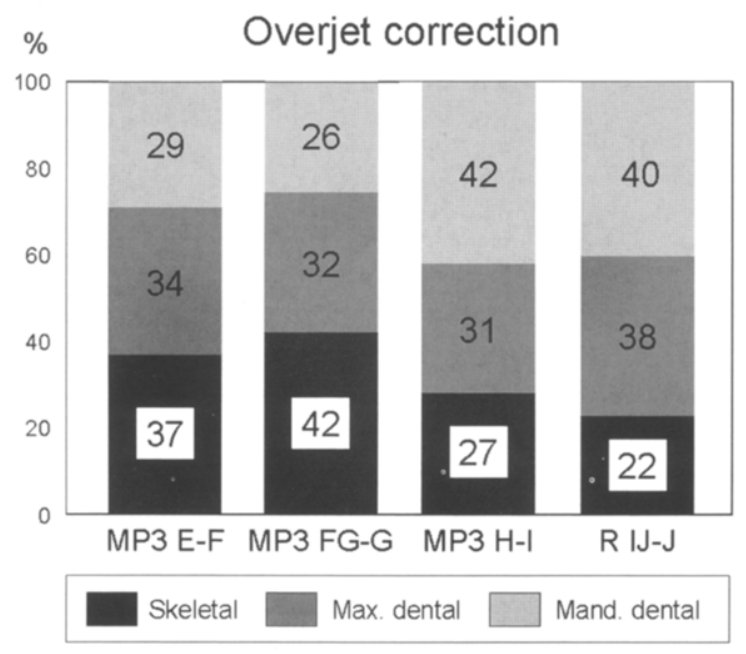

Figure 8. Percentages (\%) of skeletal and dental changes contributing to overjet correction in Herbst patients treated at different skeletal maturity stages: MP3 E-F $(n=13)$, MP3 FG-G $(n=12)$, MP3 H-I $(\mathrm{n}=$ 21), R IJJ $(\mathrm{n}=14)$.
(Bolton standards)..$^{24}$ At the end of the growth period, however, this treatment effect is no longer evident anymore (Fig 9). Therefore, the long-term total amount of mandibular growth was almost identical in the Herbst and the Bolton ideal occlusion groups. ${ }^{15}$ This was also true for the relative growth of the maxilla and the mandible; mandibular growth exceeded maxillary growth by $3.9 \mathrm{~mm}$ in the Herbst and by $4.1 \mathrm{~mm}$ in the Bolton cases (Fig 9). Thus, in Class II subjects, Herbst treatment improves the basal jaw relationship but does not normalize it compared with ideal occlusion subjects exhibiting normal growth. ${ }^{15.17 .18}$ Despite the fact that mandibular growth is improved but not normalized, a stable Class I occlusion was found in $79 \%$ of 53 Herbst patients analyzed 5 to 10 years after treatment. ${ }^{16}$ A relapse in overjet and/or molar relation was mainly the result of posttreatment dental changes, especially in the maxilla, ${ }^{19}$ and was seen more frequently in early treated Herbst patients. ${ }^{20}$ In prepeak patients, overjet and/or molar relationship relapse was found in about $30 \%$ of the subjects. In postpeak patients, relapse in overjet was seen in only $8 \%$ of patients, and relapse in molar relationship was observed in none of the subjects. The most frequent relapse promoting factors identified were early treatment, unstable occlusion, and persisting habits. ${ }^{20}$ 


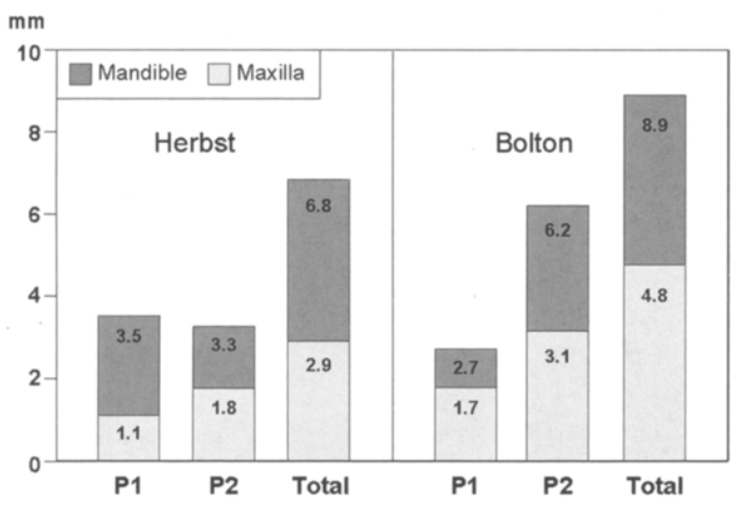

Figure 9. Maxillary and mandibular skeletal changes $(\mathrm{mm})$ contributing to Class II correction in 32 Class II, Division 1 malocclusions (16 girls and 16 boys) treated with the Herbst appliance and 32 Class I Controls (Bolton standards). P1, observation period 1 from before treatment to 6 months post-treatment; $P$ 2 , observation period 2 from 6 months post-treatment until the end of growth; Total, total observation period from before treatment until the end of growth.

In late treated Herbst patients, generally all permanent teeth were completely erupted, thus promoting a good interdigitation of the cusps of the teeth after therapy. Teeth in a stable Class I intercuspation will certainly transfer maxillary growth forces to the mandible or vice versa and may therefore coordinate maxillary and mandibular growth, thus counteracting an unfavorable posttreatment growth pattern. Therefore, a stable intercuspation is an essential factor for the prevention of both dental as well as skeletal posttreatment relapses. ${ }^{3-5,19,20,29}$

Long-term stability of the occlusion in young adults treated with the Herbst appliance has not yet been shown scientifically. However, young adults are always in the permanent dentition and have minimal, if any, residual growth that might compromise the treatment result because of unfavorable growth causing relapse. Thus, young adults treated with the Herbst appliance would seem to have optimal conditions for longterm occlusal stability (Fig 5).

\section{A New Concept for Class II Therapy}

The current and widely accepted concept of skeletal Class II treatment is (1) growth modification (with functional appliances and/or headgear) in prepeak and peak patients, (2) camouflage orthodontics (extractions of teeth and fixed appliances) in postpeak patients, and (3) orthognathic surgery in adults (Fig 10).

Because of the results from our latest Herbst studies and especially with respect to the following factors, we are of the opinion that it is time to revise the prevailing concept.

1. In young adults condylar and glenoid fossa growth can be reactivated and altered favorably on a regular basis. ${ }^{6,7}$

2. In young adults, on average, $22 \%$ of skeletal changes contribute to overjet correction. ${ }^{13}$

3. Comparable changes in sagittal jaw base relationship and in the skeletal profile are observed in young adult Herbst and orthognathic surgery (mandibular sagittal split osteotomy) patients. ${ }^{30}$

The new concept of Class II treatment ${ }^{31,32}$ proposes the following: (1) growth modification in children and adolescents as well as in postadolescents and young adults (up to the age of 25 years), (2) camouflage orthodontics, and (3) orthognathic surgery in older adults (Fig 11).

Growth modification in children should be performed with removable functional appliances and/or headgear. In adolescents, postadolescents and young adults the Herbst appliance should be used.

\section{Conclusion}

With respect to maximum mandibular growth stimulation and long-term stability of treatment,

\section{Current concept}

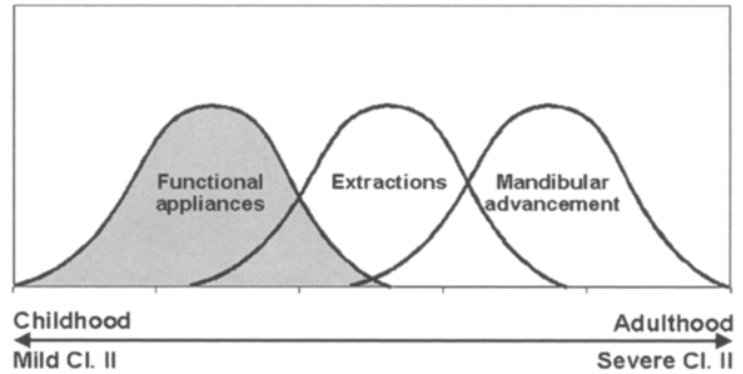

Figure 10. The current concept of Class II therapy: frequency distribution of the treatment options growth modification, camouflage orthodontics and orthognathic surgery in relation to growth development and malocclusion severity. The illustration is a visual expression of a theory and is not based on quantitative scientific data. 
New concept

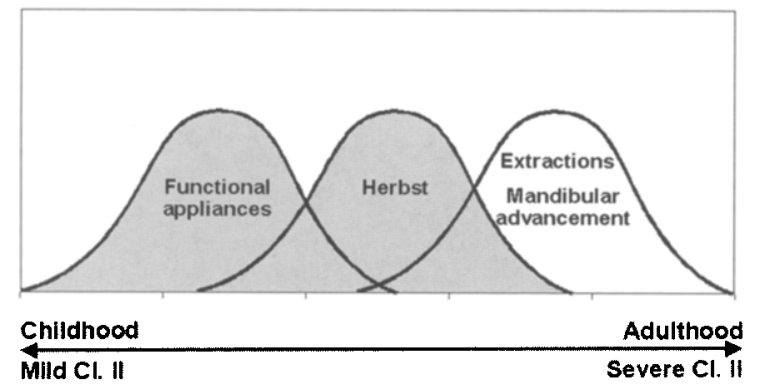

Figure 11. The new concept of Class II therapy: frequency distribution of the treatment options growth modification, camouflage orthodontics, and orthognathic surgery in relation to growth development and malocclusion severity. The illustration is a visual expression of a theory and is not based on quantitative scientific data.

the ideal period for the Herbst appliance is in the permanent dentition at or just after the pubertal peak of growth corresponding to the skeletal maturity stages $\mathrm{FG}$ to $\mathrm{H}$ of the middle phalanx of the third finger (implying the precapping to preunion stages of the ephiphysis and metaphysis). Because mandibular growth stimulation using the Herbst appliance is also possible in postadolescent young adult subjects, a new concept of Class II therapy is proposed in which the Herbst appliance is used as an alternative to orthognathic surgery in older Class II subjects.

\section{References}

1. Aelbers CM, Dermaut LR. Orthopedics in orthodontics: Part I. Fiction or reality-A review of the literature. Am J Orthod Dentofacial Orthop 1996;110:513-519.

2. Pancher\% H. Treatment of Class II malocclusions by jumping the bite with the Herbst appliance. A cephalometric investigation. Am J Orthod 1979;76:423-442.

3. Pancherz H. The mechanism of Class II correction in Herbst appliance treatment. A cephalometric investigation. Am J Orthod 1982;82:104-113.

4. Pancherz $\mathrm{H}$. The Herbst appliance-Its biologic effects and clinical use. Am J Orthod 1985;87:1-20.

5. Pancherz H, Hansen K. Occlusal changes during and after Herbst treatment: $A$ cephalometric investigation. Eur J Orthod 1986;8:215-228.

6. Ruf S, Pancherz H. Kiefergelenkwachstumsadaptation bei jungen Erwachsenen während Behandlung mit der Herbst-Apparatur. Eine prospektive magnetresonanztomographische und kephalometrische Studie. Inf Orthod Kieferor thop 1998;30:735-750.

7. Ruf S, Pancherz H. Temporomandibular joint remodeling in adolescents and voung adults during Herbst treat- ment: A prospective longitudinal magnetic resonance imaging and cephalometric radiographic investigation. Am J Orthod Dentofacial Orthop 1999;115:607-618.

8. Hägg U, Pancherz H, Taranger J. Pubertal growth and orthodontic treatment. In: Carlson DS, Ribbens KA editors. Craniofacial growth during adolescence. Monograph 20, Craniofacial Growth Series. Ann Arbor, MI: Center for human growth and development. The University of Michigan, 1987:87-115.

9. Hägg U, Pancherz H. Dentolacial orthopaedics in relation to chronological age, growth period and skeletal development. An analysis of 72 male patients with Class II division 1 malocclusion treated with the Herbst appliance. Eur J Orthod 1988;10:169-176.

10. Konik M, Pancherz H. Hansen K. The mechanism of Class II correction in late Herbst treatment. Am J Orthod Dentofacial Orthop 1997;112:87-91.

11. Panchere H, Hägg U. Dentofacial orthopedics in relation to somatic maturation. An analvsis of 70 consecutive cases treated with the Herbst appliance. Am J Orthod $1985 ; 88: 273-287$.

12. Pancher. H, Litmann C. Somatische Reife und morphologische Veränderungen des Unterkiefers bei der HerbstBchandlung. Inf Orthod Kieferorthop 1988;20:455-470.

13. Ruf S. Panchery H. Dentoskeletal effects and facial profile changes in young adults treated with the Herbst appliance. Angle Orthod 1999;69:239-246.

14. Hansen K. Panchers H. Hägg L. Long-term effects of the Herbst appliance in relation to the treatment growth period: A cephalometric study. Eur J Orthod 1991;13: 471-481.

15. Hansen K, Pinchery H. Long-term elfects of Herbst treatment in relation to normal growth development: A cephalometric study. Fur J Orthod 1992;14:285-295.

16. Hansen $\mathrm{K}$, Iemamnucisuk $\mathrm{P}$, Pancher\% H. Long-tem effects of the Herbst appliance on the dental arches and arch relationships: A biometric studv. Br J Orthod 1995; 22:123-1.34.

17. Pancher H, Liumann C. Morphologie und Lage des Lnterkiefers bei der Herbst-Behandlung. Eine kephalometrische Analyse der Veränderungen bis zum Wachsunnsabschluß. Inf Orthod Kieferorthop 1989:21:493-513.

18. Panchers. H, Fackel U. The skeletofacial growth pattem pre- and post-dentofacial onthopaedics. A long-term study of Class II malocclusions treated with the Herbst appliance. Eur J Orthod 1990;12:209-218.

19. Pancherz $\mathrm{H}$. The mature of Class II relapse alter Herbst appliance treatment: A cephalometric long-term investigation. Am J Orthod Dentofacial Orthop 1991;100:220-233.

20. Panchere I1. Früh- oder Spätbchandlung mit der HerbstApparatur - Stabilität oder Rezidiv? Inf Orthod Kieferorthop 1994;26:437-445.

21. Hägg $L$, Taranger J. Skeletal stages of the hand and wrist as indicators of the pubertal growth spurt. Actat Odontol Scand 1980;38:187-200.

22. Ruf S, Panchers. H. Temporomandibular joint growth adaptation in Herbst treatment: A prospective magnetic resonance imaging and cephalometric roentgenographic study. Eur J Orthod 1998;20:375-388.

23. Weaver $N$, Glover $K$, Major $P$, et al. Age limitation on provision of orthopedic therapy and orthognathic surgery. Am J Orthod Dentofacial Orthop 1998:113:156-164. 
24. Angle EH. Malocclusion of the teeth. Philadelphia, PA: SS White Dental Mfg Co, 1907.

25. Bass NM. Orthopedic coordination of dentofacial development in skeletal Class II malocclusion in conjunction with edgewise therapy. Part II. Am J Orthod 1983;84:466-490.

26. Bass NM. Orthopedic coordination of dentofacial development in skeletal Class II malocclusion in conjunction with edgewise therapy. Part I. Am J Orthod 1983;84:361383.

27. Wieslander L. Intensive treatment of severe Class II malocclusions with a headgear-Herbst appliance in the early mixed dentition. Am J Orthod 1984;86:1-13.

28. Broadbent BH, Broadbent BH, Jr., Golden W. Bolton standards of dentofacial development growth. St. Louis, MO: Mosby, 1975.

29. Wieslander L. Long-term effects of treatment with the
headgear-Herbst appliance in the early mixed dentition. Stability or relapse? Am J Orthod Dentofacial Orthop 1993;104:319-329.

30. Kruse J, Ruf S, Pancherz H, Hansen K. Treatment of adult Class II malocclusions: Herbst versus orthognathic surgery. Eur J Orthod 2000;22:450 (abstr).

31. Pancherz H. Dentofacial orthopedics or orthognathic surgery: Is it a matter of age? Am J Orthod Dentofacial Orthop 2000;117:571-574.

32. Pancherz $H$, von Bremen J. Efficiency of Class II, Division 1 therapy in relation to treatment timing and modality. In: McNamara JA, Kelly KA editors. Treatment timing: orthodontics in four dimensions. Monograph 39, Craniofacial Growth Series. Ann Arbor, MI: Center for human growth and development. The University of Michigan, 2002:25-53. 